\title{
Treadmill Exercise Induces Hippocampal Astroglial Alterations in Rats
}

\author{
Caren Bernardi, ${ }^{1}$ Ana Carolina Tramontina, ${ }^{2}$ Patrícia Nardin, ${ }^{2}$ Regina Biasibetti, ${ }^{2}$ \\ Ana Paula Costa, ${ }^{2}$ Adriana Fernanda Vizueti, ${ }^{2}$ Cristiane Batassini, ${ }^{2}$ Lucas Silva Tortorelli, ${ }^{2}$ \\ Krista Minéia Wartchow, ${ }^{2}$ Márcio Ferreira Dutra, ${ }^{2}$ Larissa Bobermin, ${ }^{2}$ Patrícia Sesterheim, \\ André Quincozes-Santos, ${ }^{2}$ Jaqueline de Souza, ${ }^{2}$ and Carlos Alberto Gonçalves ${ }^{1,2}$ \\ ${ }^{1}$ Programa de Pós-Graduação em Neurociências, Instituto de Ciências Básicas da Saúde, Universidade Federal do Rio Grande do Sul, \\ 90046-900 Porto Alegre, RS, Brazil \\ ${ }^{2}$ Departamento de Bioquímica, Instituto de Ciências Básicas da Saúde, Universidade Federal do Rio Grande do Sul, \\ 90035-003 Porto Alegre, RS, Brazil
}

Correspondence should be addressed to Carlos Alberto Gonçalves; casg@ufrgs.br

Received 3 September 2012; Revised 23 November 2012; Accepted 3 December 2012

Academic Editor: Michel Baudry

Copyright (C) 2013 Caren Bernardi et al. This is an open access article distributed under the Creative Commons Attribution License, which permits unrestricted use, distribution, and reproduction in any medium, provided the original work is properly cited.

\begin{abstract}
Physical exercise effects on brain health and cognitive performance have been described. Synaptic remodeling in hippocampus induced by physical exercise has been described in animal models, but the underlying mechanisms remain poorly understood. Changes in astrocytes, the glial cells involved in synaptic remodeling, need more characterization. We investigated the effect of moderate treadmill exercise ( $20 \mathrm{~min} /$ day) for 4 weeks on some parameters of astrocytic activity in rat hippocampal slices, namely, glial fibrillary acidic protein (GFAP), glutamate uptake and glutamine synthetase (GS) activities, glutathione content, and S100B protein content and secretion, as well as brain-derived neurotrophic factor (BDNF) levels and glucose uptake activity in this tissue. Results show that moderate treadmill exercise was able to induce a decrease in GFAP content (evaluated by ELISA and immunohistochemistry) and an increase in GS activity. These changes could be mediated by corticosterone, whose levels were elevated in serum. BDNF, another putative mediator, was not altered in hippocampal tissue. Moreover, treadmill exercise caused a decrease in NO content. Our data indicate specific changes in astrocyte markers induced by physical exercise, the importance of studying astrocytes for understanding brain plasticity, as well as reinforce the relevance of physical exercise as a neuroprotective strategy.
\end{abstract}

\section{Introduction}

Studies have shown that physical exercise can have profound effects on cardiovascular, pulmonary, and the musculoskeletal system, as well as the central nervous system (CNS) $[1,2]$. Moderate physical activity improves memory and learning [3-8] and is associated with a lower risk for Alzheimer's dementia [9], Parkinson's disease [10] and other types of neurodegenerative diseases [2]. One of the regions of CNS more affected by exercise is the hippocampus. A putative mechanism, through which the exercise exerts its effects on the hippocampus, is the induction of brain-derived neurotrophic factor (BDNF) [11].

Astrocytes, the most abundant glial cells, particularly those of the glutamatergic type, are very important elements in neurotransmission $[12,13]$ and antioxidant defense, and this action involves the synthesis and secretion of glutathione (GSH) [14]. These cells are responsible for glutamate removal from the synaptic cleft and its conversion, through glutamine synthetase (GS) catalysis, into glutamine for replacement in the neurons. Moreover, increments in energy demand and functional activity during exercise may require functional and structural alterations in astrocytes $[15,16]$, due to their involvement in the blood brain barrier [17].

The involvement of astrocytes in brain plasticity is commonly related to changes in specific proteins, such as glial fibrillary acidic protein (GFAP), S100B, glutamate transporters and glutamine synthetase. With regard to BDNF, it is important to mention that this neurotrophin, which is 
TABLE 1: Experimental sets of rats submitted to treadmill exercise.

\begin{tabular}{lrlc}
\hline $\begin{array}{l}\text { Experimental } \\
\text { set }\end{array}$ & $N$ & Biochemical assays & Samples \\
\hline 1 & 11 & $\begin{array}{l}\text { Corticosterone } \\
\text { Immunohistochemistry for }\end{array}$ & Blood \\
& 20 & $\begin{array}{l}\text { GFAP; ELISA for GFAP, } \\
\text { S100B, and BDNF; GSH } \\
\text { and NO measurement }\end{array}$ & $\begin{array}{c}\text { Hippocampal } \\
\text { tissue }\end{array}$ \\
3 & 17 & $\begin{array}{l}\text { Glutamate uptake and } \\
\text { S100B secretion in slices }\end{array}$ & $\begin{array}{c}\text { Hippocampal } \\
\text { tissue }\end{array}$ \\
\hline
\end{tabular}

Adult Wistar rats were submitted to 4 weeks ( 20 min, 5 times a week) of treadmill exercise. At $2 \mathrm{~h}$ (set 1 ) or $24 \mathrm{~h}$ (sets 2 and 3 ) after the last exercise session, rats were anesthetized, killed, and samples were collected for the biochemical assays, as described in Section 2.

de novo synthesized in neurons, is released as mature BDNF and pro-BDNF, and that pro-BDNF is uptaken and released by astrocytes [18]. Therefore, recycling of BDNF by astrocytes seems to contribute to the regulation of synaptic plasticity [19].

Physical exercise induces biochemical alterations in astrocytes [20-23] and enhances the behavioral performance of animals in spatial memory tasks $[7,20,24]$. The contribution of astrocytes to the brain plasticity induced by physical exercise needs further characterization. This study aimed to investigate the effect of moderate exercise for 4 weeks on some parameters of astrocytic activity in the rat hippocampus.

\section{Material and Methods}

2.1. Animals. Forty-eight male Wistar rats (90 days old, weighing 250-320 g) were obtained from our breeding colony (at the Department of Biochemistry, Federal University of Rio Grande do Sul) and were maintained under controlled light and environmental conditions ( $12 \mathrm{~h}$ light/12 h dark cycle at a constant temperature of $22 \pm 1^{\circ} \mathrm{C}$ ) with free access to food and water. All animal experiments were carried out in accordance with the Directive 2010/63/EU of the European parliament and following the regulations of the local animal house authorities. Rats were habituated with the treadmill apparatus to minimize novelty stress and submitted to maximal exercise test. After the test, rats that refused to run or who had the worst performance were assigned to the control/sedentary group (SED) $(N=24)$. The other animals were assigned to the exercise group (EXE) $(N=24)$. Three sets of experiments were carried out separately (Table 1).

2.2. Adaptation to Treadmill and Maximal Exercise Test. To perform the training, all animals were adapted to walk on a treadmill for three consecutive days (days 1 to 3 ). This adaptation consisted of walking on a treadmill for $10 \mathrm{~min}$ at $5 \mathrm{~m} / \mathrm{min}$. On the fourth day, animals were submitted to the maximal exercise test (MET). The MET was used to determine the maximal exercise capacity (MEC). The test consisted of a graded exercise on the treadmill, with speed increments of $5 \mathrm{~m} / \mathrm{min}$ every $3 \mathrm{~min}$, starting at $5 \mathrm{~m} / \mathrm{min}$ and continuing up to the MEC of each rat [25]. Values attained in the MET were used to plan the treadmill training program.

2.3. Treadmill Training. The exercise training consisted of running sessions on an adapted motorized rodent treadmill (INBRAMED TK 01, Porto Alegre, Brazil) at $60 \%$ of MEC (maximal velocity). Treadmill training was performed between 8:00 and 12:00 h. The animals ran for 20 minutes, 5 days a week, for 4 weeks. Selected animals that initially refused to run were encouraged by gently tapping their backs. Neither electric shock nor physical prodding was used in this study. The control/sedentary group was transported to the experimental room and handled exactly as the experimental animals were and maintained in the turned off treadmill for 5 min without forcing them to run [26].

2.4. Serum Samples. Two hours after the last exercise session (20 min/day, 5 days/week during four weeks) animals $(n=$ 5-6) were anesthetized with ketamine and xylazine (75 and $10 \mathrm{mg} / \mathrm{kg}$, resp., i.p.), and then whole blood was obtained through an intracardiac puncture using a $0.37 \mathrm{~mm}$ diameter needle that was inserted into the intercostal space above the sternum. Serum was separated by centrifugation at $3000 \times \mathrm{g}$ for $5 \mathrm{~min}$. Serum samples were frozen $\left(-20^{\circ} \mathrm{C}\right)$ until further analysis [27].

2.5. Hippocampal Tissue Samples. Twenty-four hours after the last exercise session (20 $\mathrm{min} /$ day, 5 days/week during four weeks) the animals were killed by decapitation, brains were removed and placed in cold saline medium with the following composition (in $\mathrm{mM}$ ): $120 \mathrm{NaCl} ; 2 \mathrm{KCl} ; 1 \mathrm{CaCl}_{2} ; 1 \mathrm{MgSO}_{4}$; $25 \mathrm{HEPES} ; 1 \mathrm{KH}_{2} \mathrm{PO}_{4}$ and 10 glucose, adjusted to $\mathrm{pH} 7.4$, and previously aerated with $\mathrm{O}_{2}$. The hippocampi were dissected out, and transverse slices of $0.3 \mathrm{~mm}$ were obtained using a McIlwain Tissue Chopper. Slices were transferred immediately to 24 -well culture plates, each well contains $0.3 \mathrm{~mL}$ of the solution described previously for measuring S100B secretion and $0.3 \mathrm{~mL}$ of HBSS (Hank's balanced salt solution) for measuring glutamate uptake and glucose uptake. Slice samples (hippocampus) were then frozen $\left(-80^{\circ} \mathrm{C}\right)$ for biochemical measurements, described as follows.

2.6. Quantification of S100B and GFAP. S100B content in the hippocampus was measured by ELISA [28]. Briefly, $50 \mu \mathrm{L}$ of sample plus $50 \mu \mathrm{L}$ of tris buffer were incubated for $2 \mathrm{~h}$ on a microtiter plate previously coated with monoclonal antiS100B (SH-B1). Polyclonal anti-S100B was incubated for $30 \mathrm{~min}$ and then peroxidase-conjugated anti-rabbit antibody was added for a further $30 \mathrm{~min}$. A colorimetric reaction with o-phenylenediamine was measured at $492 \mathrm{~nm}$. The standard S100B curve ranged from 0.019 to $10 \mathrm{ng} / \mathrm{mL}$. ELISA for GFAP [29] was carried out by coating the microtiter plate with $100 \mu \mathrm{L}$ samples containing $30 \mu \mathrm{g}$ of protein for overnight at $4^{\circ} \mathrm{C}$. Incubation with a rabbit polyclonal anti-GFAP for $2 \mathrm{~h}$ was followed by incubation with a secondary antibody conjugated with peroxidase for $1 \mathrm{~h}$, at room temperature; the standard GFAP curve ranged from 0.1 to $10 \mathrm{ng} / \mathrm{mL}$. 
2.7. Immunohistochemistry for GFAP. Rats were anesthetized using ketamine/xylazine (75 and $10 \mathrm{mg} / \mathrm{kg}$, resp., i.p.) and were perfused through the left cardiac ventricle with $200 \mathrm{~mL}$ of saline solution, followed by $200 \mathrm{~mL}$ of $4 \%$ paraformaldehyde in $0.1 \mathrm{M}$ phosphate buffer saline (PBS), pH 7.4. After perfusion, the brains were removed, postfixed in the same fixative solution for $4 \mathrm{~h}$ at room temperature, and cryoprotected by immersion in $15 \%$ and $30 \%$ sucrose solution in PBS at $4^{\circ} \mathrm{C}$. The brains were then frozen by immersion in isopentane cooled with $\mathrm{CO}_{2}$ and stored in a freezer $\left(-80^{\circ} \mathrm{C}\right)$ for later analyses [30]. Coronal slices $(45 \mu \mathrm{m})$ were obtained at $-20^{\circ} \mathrm{C}$ using a cryostat (Leitz). The free-floating sections were incubated with polyclonal anti-GFAP from rabbit, diluted $1: 3000$ in PBS-Triton X-100 $0.4 \%$ and $2 \%$ bovine serum albumin (BSA), for $48 \mathrm{~h}$ at $4^{\circ} \mathrm{C}$. After washing several times in PBS, tissue sections were incubated with anti-rabbit Alexa 488 (Molecular Probes) diluted 1:500 in PBS-TX 0.1\% and $2 \%$ BSA for $1 \mathrm{~h}$ at room temperature. Afterwards, the sections were washed several times in PBS, mounted on slides with Fluor Save, and covered with coverslips. The images were obtained with a Confocal Olympus IX-81microscope.

2.8. Glutamate Uptake Assay. Glutamate uptake was performed as previously described [31]. Briefly, hippocampal slices were transferred to 24-well plates and incubated for $23 \mathrm{~min}$ at $37^{\circ} \mathrm{C}$ in a Hank's balanced salt solution (HBSS) containing (in $\mathrm{mM}$ ): $137 \mathrm{NaCl}, 5.36 \mathrm{KCl}, 1.26 \mathrm{CaCl}_{2}, 0.41$ $\mathrm{MgSO}_{4}, 0.49 \mathrm{MgCl}_{2}, 0.63 \mathrm{Na}_{2} \mathrm{HPO}_{4} \cdot 7 \mathrm{H}_{2} \mathrm{O}, 0.44 \mathrm{KH}_{2} \mathrm{PO}_{4}$, $4.17 \mathrm{NaHCO}_{3}$, and 5.6 glucose, adjusted to $\mathrm{pH}$ 7.4. The assay was started by the addition of $0.1 \mathrm{mM}$ L-glutamate and $0.33 \mu \mathrm{Ci} / \mathrm{mL} \mathrm{L}-\left[2,3-{ }^{3} \mathrm{H}\right]$ glutamate. Incubation was stopped after $5 \mathrm{~min}$ by removal of the medium and rinsing the slices twice with ice-cold HBSS. The slices were then lysed in a solution containing $0.5 \mathrm{M} \mathrm{NaOH}$. Radioactivity was measured in a scintillation counter. Sodium-independent uptake was determined using $\mathrm{N}$-methyl-D-glucamine instead of $\mathrm{NaCl}$. Sodium-dependent glutamate uptake was obtained by subtracting the nonspecific uptake of the total uptake to obtain the specific uptake. Results ( $\mathrm{nmol} / \mathrm{mg}$ protein/min) were expressed as a percentage of the control.

2.9. Glutamine Synthetase (GS) Activity. The enzymatic assay was performed, as described previously [32]. Briefly, homogenized tissue samples were added to a reaction mixture containing (in $\mathrm{mM}$ ): $10 \mathrm{MgCl}_{2} ; 50$ L-glutamate; 100 imidazole- $\mathrm{HCl}$ buffer ( $\mathrm{pH}$ 7.4); 10 2-mercaptoethanol; 50 hydroxylamine- $\mathrm{HCl} ; 10 \mathrm{ATP}$ and incubated for $15 \mathrm{~min}$ at $37^{\circ} \mathrm{C}$. The reaction was stopped by the addition of $0.4 \mathrm{~mL}$ of a solution containing: $370 \mathrm{mM}$ ferric chloride; $670 \mathrm{mM}$ $\mathrm{HCl} ; 200 \mathrm{mM}$ trichloroacetic acid. After centrifugation, the supernatant was measured at $530 \mathrm{~nm}$ and compared to the absorbance generated by standard quantities of $\gamma$-glutamylhydroxamate treated with ferric chloride reagent. Glutamine synthetase activity was expressed as $\mu \mathrm{mol} / \mathrm{mg}$ $\mathrm{prot} / \mathrm{min}$.

2.10. Glutathione (GSH) Content Assay. GSH levels were measured as previously described [33]. This assay detects only the reduced glutathione content. Briefly, homogenized slices were assayed in sodium phosphate buffer (0.1 M, pH 8.0), and protein was precipitated with $1.7 \%$ meta-phosphoric acid. Supernatant was assayed with $o$-phthaldialdehyde $(1 \mathrm{mg} / \mathrm{mL}$ methanol) at room temperature for $15 \mathrm{~min}$. Fluorescence was measured using excitation and emission wave lengths of 350 and $420 \mathrm{~nm}$, respectively. A calibration curve was performed with standard glutathione solutions $(0-500 \mu \mathrm{M})$. Glutathione concentrations were expressed as $\mathrm{nmol} / \mathrm{mg}$ protein.

2.11. NO Assay. NO metabolites, $\mathrm{NO}_{3}$-(nitrate), and $\mathrm{NO}_{2}$-(nitrite) were determined according to [34]. Briefly, homogenates from hippocampal were mixed with $25 \%$ trichloroacetic and centrifuged at $1800 \mathrm{~g}$ for $10 \mathrm{~min}$. The supernatant was immediately neutralized with $2 \mathrm{M}$ potassium bicarbonate. $\mathrm{NO}_{3}^{-}$was reduced to $\mathrm{NO}_{2}^{-}$by nitrate reductase. The total $\mathrm{NO}_{2}^{-}$in the incubation was measured by a colorimetric assay at $540 \mathrm{~nm}$, based on the Griess reaction. A standard curve was performed using sodium nitrite $(0-80 \mu \mathrm{M})$. Results were expressed as $\mu \mathrm{M}$ of nitrite/mg protein.

2.12. Evaluation of Intracellular Reactive Oxygen Species (ROS) Production. Intracellular ROS production was detected using the nonfluorescent cell permeating compound, $2^{\prime}-7^{\prime}$-dichlorofluorescein diacetate (DCF-DA). Samples homogenized in sodium phosphate buffer, $\mathrm{pH} 7.4$ with $140 \mathrm{mM} \mathrm{KCl}$ were treated with DCF-DA $(10 \mu \mathrm{M})$ for $30 \mathrm{~min}$ at $37^{\circ} \mathrm{C}$. The fluorescence was measured in a plate reader (Spectra Max GEMINI XPS, Molecular Devices, USA) with excitation at $485 \mathrm{~nm}$ and emission at $520 \mathrm{~nm}$, as described previously [35]. Values are obtained as a unit of fluorescence/mg protein and are expressed as percentage of control.

2.13. Glucose Uptake. Glucose uptake was performed in hippocampal slices. Briefly, slices were transferred to 24-well plates and incubated for $30 \mathrm{~min}$ at $37^{\circ} \mathrm{C}$ in a Hank's balanced salt solution (HBSS) containing (in $\mathrm{mM}$ ): $137 \mathrm{NaCl}, 5.36 \mathrm{KCl}$, $1.26 \mathrm{CaCl}_{2}, 0.41 \mathrm{MgSO}_{4}, 0.49 \mathrm{MgCl}_{2}, 0.63 \mathrm{Na}_{2} \mathrm{HPO}_{4} \cdot 7 \mathrm{H}_{2} \mathrm{O}$, $0.44 \mathrm{KH}_{2} \mathrm{PO}_{4}, 4.17 \mathrm{NaHCO}_{3}$, and 5.6 glucose, adjusted to $\mathrm{pH}$ 7.4. The assay was started by addition of $0.1 \mu \mathrm{Ci} / \mathrm{mL}[2,3-$ $\left.{ }^{3} \mathrm{H}\right]$-D-glucose. The incubation was stopped after $30 \mathrm{~min}$ by removal of the medium and rinsing the slices twice with ice-cold HBSS. The slices were then lysed in a solution containing $0.5 \mathrm{M} \mathrm{NaOH}$. Radioactivity was measured in a scintillation counter. Nonspecific uptake was determined by using $25 \mu \mathrm{M}$ cytochalasin B. Final glucose uptake was obtained by subtracting the nonspecific uptake of the total one to obtain the specific uptake.

2.14. Corticosterone Enzyme Immunoassay (EIA). Corticosterone concentrations in serum were measured using a commercial EIA kit conforming the manufacturer's protocol (Cayman Chemicals, MI, USA). Briefly, $50 \mu \mathrm{L}$ aliquots were added to 96-well plates precoated with rabbit antisheep IgG antibody. We added corticosterone-specific acetylcholinesterase tracer and specific corticosterone antiserum 


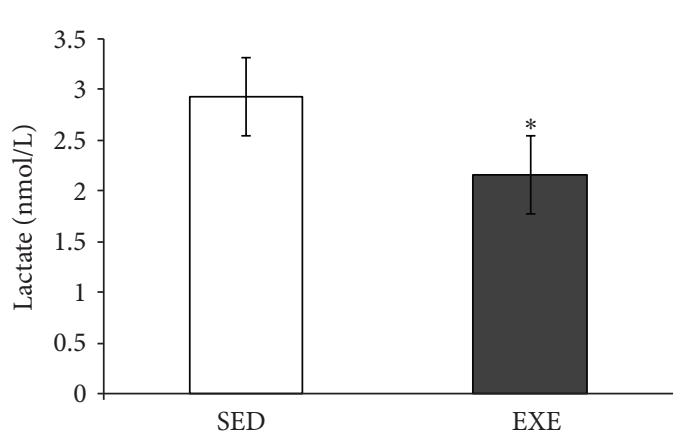

(a)

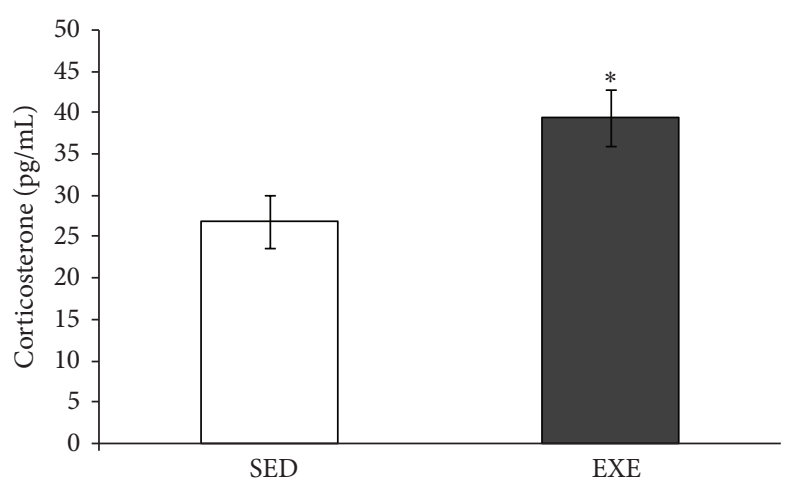

(b)

FIGURE 1: Moderate treadmill exercise increased serum corticosterone but decreased lactate levels. The blood lactate and serum corticosterone levels of rats submitted to 4 weeks ( $20 \mathrm{~min} /$ day, 5 days/week during four weeks) of treadmill exercise. The blood lactate level was measured with a lactate analyzer (a), and serum corticosterone was measured by ELISA (b). Values are mean \pm standard error of control/sedentary $(\mathrm{SED})(n=5)$ and exercise (EXE) group $(n=6) .{ }^{*}$ means significantly different from other group (Student's $t$-test, $\left.P<0.05\right)$.

and then placed plates on an orbital shaker for two hours. Plates were then developed and read at $412 \mathrm{~nm}$. The concentration of corticosterone was calculated by comparing samples to the standard curve generated with the kit.

2.15. BDNF Concentration. BDNF protein was assessed using the ChemiKine brain-derived neurotrophic factor (BDNF) Sandwich ELISA kit (Millipore, USA), according to the manufacturer's recommendations. Briefly, the slices of hippocampus were individually homogenized in buffer containing $100 \mathrm{mM}$ Tris- $\mathrm{HCl}$ ( $\mathrm{pH} 7.0$ ), containing $2 \%$ bovine serum albumin (BSA), $1 \mathrm{M} \mathrm{NaCl}, 4 \mathrm{mM}$ EDTA $\cdot \mathrm{Na}_{2}, 2 \%$ Triton X-100, $0.1 \%$ sodium azide, and the cocktail protease inhibitors (Sigma). Samples were centrifuged for $30 \mathrm{~min}$ at $14,000 \times \mathrm{g}$. The supernatant was incubated on a $96-$ well microplate previously coated with anti-BDNF monoclonal antibody. After blocking, plates were incubated with biotinylated mouse anti-BDNF monoclonal antibody for $2 \mathrm{~h}$ and streptavidin-HRP conjugate solution for $1 \mathrm{~h}$. Then color reaction with $3,3^{\prime}, 5,5^{\prime}$-tetramethylbenzidine substrate was quantified in a plate reader at $450 \mathrm{~nm}$. The standard BDNF curve ranged from 7.8 to $500 \mathrm{pg} / \mathrm{mL}$.

2.16. Lactate Measurement. An increase in lactate level (reflecting an improved muscle metabolism) in the blood is commonly used as a marker of the effect of exercise training [36]. Blood samples were collected from a cut at the tip of the tail at the end of the last exercise bout. The lactate concentrations were determined with a lactate analyzer (Accutrend Plus, Roche Diagnostic, Germany).

2.17. Statistical Analysis. Parametric data from the experiments are presented as means \pm standard error and statistically evaluated by Student's $t$-test, assuming $P<0.05$.

\section{Results}

3.1. Exercise Protocol Characterization. In order to characterize whether the protocol for the treadmill exercise was aerobic, we analyzed the blood lactate levels in animals [37]. The concentration of blood lactate in both groups, exercise (EXE) and control/sedentary (SED), remained below the anaerobic threshold of $7.17 \pm 0.16 \mathrm{mM}$. Moreover, a significant decrease in blood lactate levels was observed in the exercise group, as compared to the control/sedentary group $(P=0.04)$ (Figure $1(\mathrm{a}))$. Serum corticosterone was used to evaluate stress responses induced by this exercise protocol. A small but significant increase was observed in serum corticosterone levels $(P=0.04$, Figure $1(b))$.

\subsection{Hippocampal Contents of BDNF and GFAP. The BDNF} content in hippocampus was not changed by this exercise protocol $(P=0.17$, Figure 2(a)). However, the mean GFAP content was decreased in exercised rats $(P=0.02$, Figure 2 (b)). The immunohistochemistry of the stratum radiatum of CA1 hippocampal region (Figure 3(a) and 3(b)) suggests a decrease in GFAP immunoreactivity.

3.3. S100B Content and Secretion in Hippocampal Slices. No significant differences in S100B content, as evaluated by ELISA, were observed in the hippocampus of rats submitted to treadmill exercise ( $P=0.92$, Figure $4(\mathrm{a})$ ). Hippocampal slice preparations from the two groups were used to evaluate in vitro S100B secretion. No significant changes in basal S100B secretion were found at $1 \mathrm{~h}$ (Figure 4(b)).

3.4. Glutamate Metabolic Parameters. This exercise protocol did not change the glutamate uptake $(P=0.56$, Figure $5(\mathrm{a}))$ in hippocampal tissue. In contrast, we observed an increase in GS activity in exercised rats $(P=0.003$, Figure $5(b))$.

3.5. Hippocampal Redox Parameters. Two parameters were investigated to evaluate oxidative stress in the hippocampus: GSH (reduced form of glutathione) and NO (nitric oxide) contents. No significant differences were observed in GSH content $(P=0.92$, Figure 6(a)). Conversely, a decrease in 


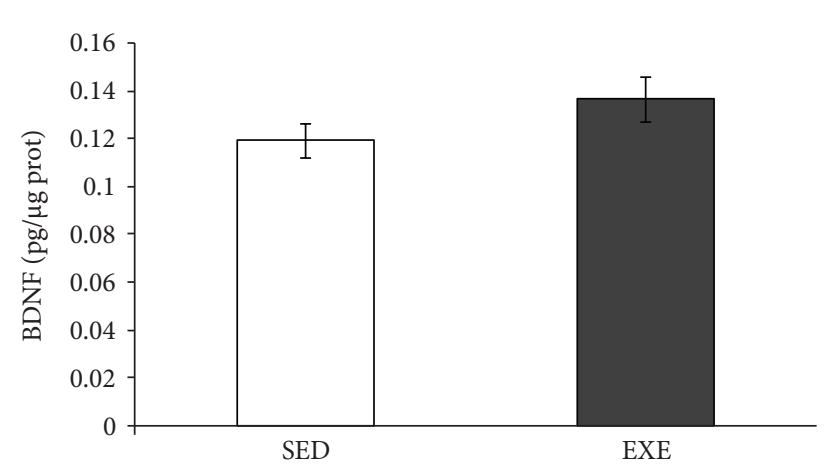

(a)

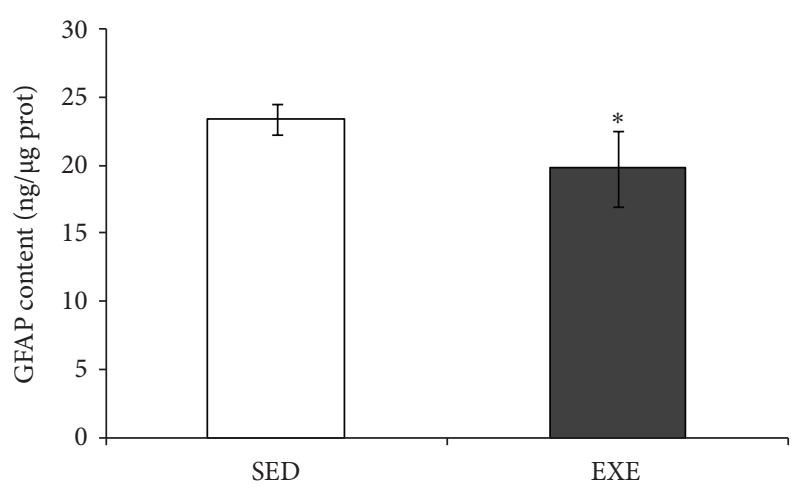

(b)

FIGURE 2: Moderate treadmill exercise decreased GFAP content in the hippocampus of exercised rats. Effects of treadmill exercise (20 min/day, 5 days/week during four weeks) on BDNF (a) and GFAP (b) contents in rat hippocampus were evaluated and were measured by ELISA. Values are mean \pm standard error of control/sedentary (SED) $(n=6)$ and exercise (EXE) group $(n=7) .{ }^{*}$ means significantly different from respective control/sedentary group (Student's $t$-test, $P<0.05$ ).

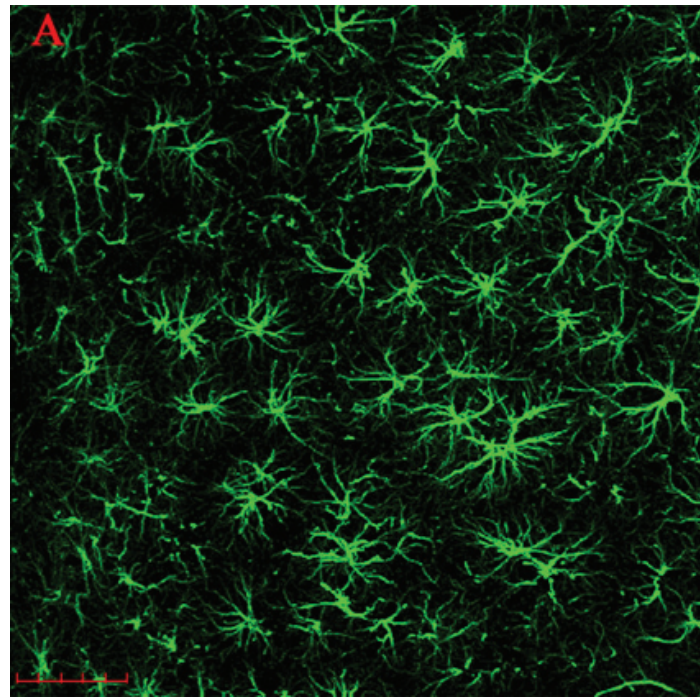

(a)

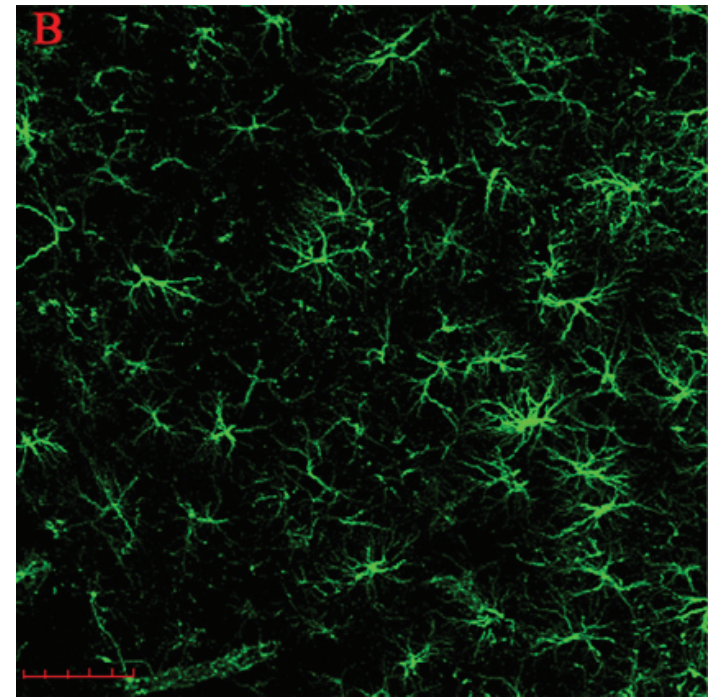

(b)

FIGURE 3: Immunohistochemistry for GFAP from rats submitted to treadmill exercise. Serial stack images obtained with an Olympus Confocal FV-1000 from GFAP immunofluorescence staining in the stratum radiatum of CA1 hippocampal region of rats submitted to treadmill exercise (20 min/day, 5 days/week during four weeks). The images showed an evident reduction in GFAP expression in control/sedentary (SED) rats (a) when compared to exercised (EXE) rats (b). Magnification of 40x, $1.0 \mu \mathrm{m}$ of optical stack thickness, and 15 confocal planes. Scale bars = $50 \mu \mathrm{m}$.

NO content (based on nitrite measurement) was found in the hippocampal tissue of exercised rats $(P=0.049$, Figure $6(\mathrm{~b}))$.

\section{Discussion}

Physical exercise has unquestionable beneficial effects on brain health. However, relatively little is known about mechanisms underlying these benefits $[2,38]$. Synaptic remodeling in hippocampus induced by physical exercise has been described in animal models (e.g., [39]). Astrocytes have been shown to play an important role in synaptic remodeling [40-42] and protecting the CNS against various pathologies [43]. The aim of this study was to evaluate the effect of moderate treadmill running on astroglial parameters in the rat hippocampus.

Our results show that 4 weeks of moderate exercise decrease the GFAP content in the rat hippocampus. This is in agreement with a decrease in the number and immunoreactivity of GFAP cells in the rat cerebral cortex after running [22]. However, there are some controversies in the literature regarding the effect of physical exercise on GFAP expression in astrocytes. Some studies have shown that physical exercise seems to increase GFAP expression in different brain regions, such as the cerebral cortex, striatum [15], and hippocampus [20]. On the other hand, some studies have not found alterations in this parameter in the rat hippocampus [21, 23]. 


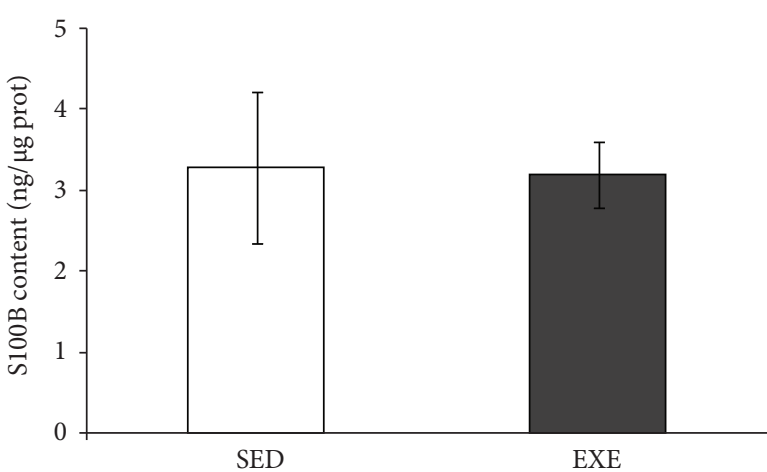

(a)

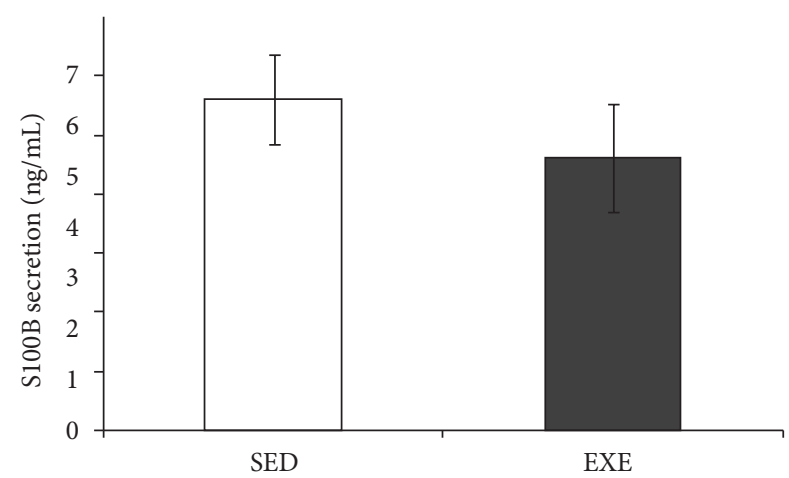

(b)

FIGURE 4: Hippocampal content and secretion of S100B were not affected by moderate treadmill training. S100B content and secretion in hippocampal slices of rats submitted to moderate treadmill exercise ( $20 \mathrm{~min} /$ day, 5 days/week during four weeks $)$ were analyzed. Hippocampi were dissected out and chopped into $0.3 \mathrm{~mm}$ slices for measurement of total S100B content (a) and basal secretion in $1 \mathrm{~h}$ (b). S100B content was measured by ELISA. Values are mean \pm standard error of control/sedentary (SED) $(n=6)$ and exercised $(\mathrm{EXE})(n=7)$ rats.

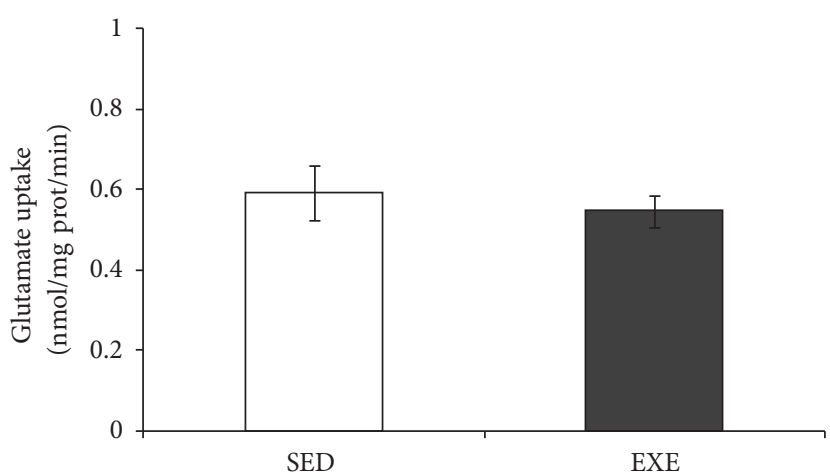

(a)

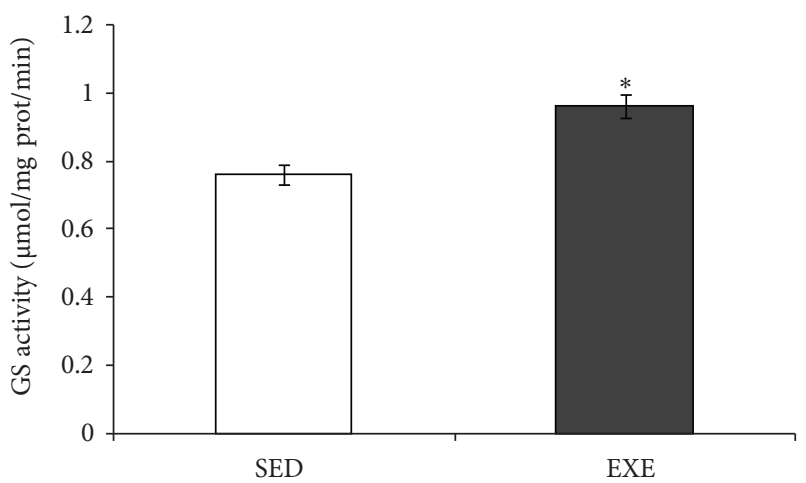

(b)

FIGURE 5: Moderate treadmill exercise increased glutamine synthetase activity in hippocampus of rats. Glutamate uptake and glutamine synthetase (GS) activity in the hippocampus of rats submitted to moderate treadmill exercise ( $20 \mathrm{~min} /$ day, 5 days/week during four weeks) were analyzed. Hippocampi were dissected out and chopped into $0.3 \mathrm{~mm}$ slices for measurement of glutamate uptake (a) or homogenized for measurement of GS activity (b). Values are mean \pm standard error of control/sedentary (SED) $(n=8)$ and exercise (EXE) ( $n=9)$ group. ${ }^{*}$ means significant differences from control (Student's $t$-test, $P<0.05$ ).

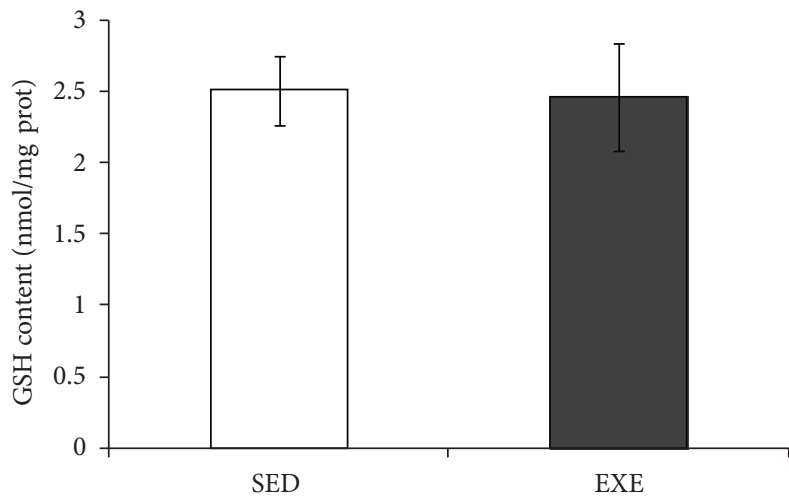

(a)

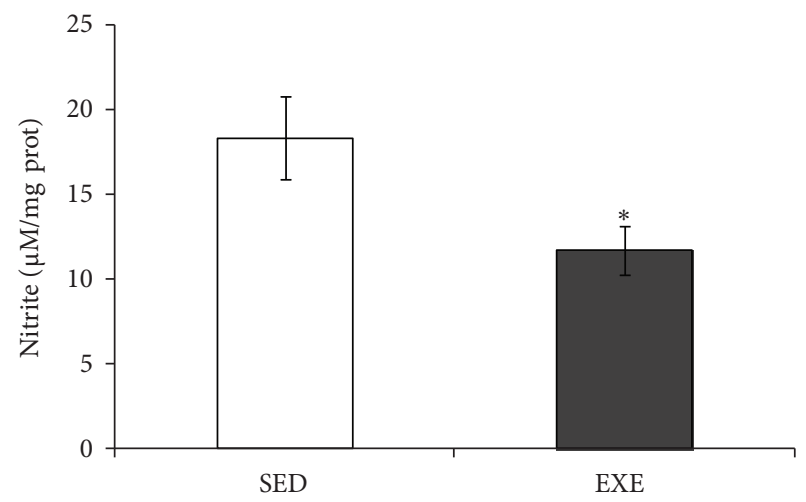

(b)

FIgURE 6: Moderate treadmill exercise decreased NO levels in hippocampus of rats. GSH (reduced form of gluthatione) and NO content in the hippocampus of rats submitted to treadmill exercise $(20 \mathrm{~min} /$ day, 5 days/week during four weeks) were analyzed. Twenty-four hours after the last session of exercise, hippocampi were dissected out and homogenized for measurement of GSH (a) or NO (b). Values are mean \pm standard error of control/sedentary (SED) $(n=6)$ and exercise (EXE) $(n=7)$ group. ${ }^{*}$ means significantly different from respective control/sedentary group (Student's $t$-test, $P<0.05$ ). 
The discrepancy in results probably arises from methodological differences, including brain regions, exercise protocol (frequency, intensity), and duration of exercise training [44]. Moreover, we cannot rule out that the hippocampal changes observed (on GFAP and other parameters) reflect differences in rats, based on inherent differences; that is, rats that eagerly exercised versus rats that refused to run during the initial exercise test. However, blood lactate levels measured previously to this test were not altered (data not shown).

Lactate is an important energetic substrate for the brain, and it has been proposed that an increment of blood lactate, during physical activity, could induce brain changes [45]. Interestingly, we found a decrease in serum lactate with our protocol of physical activity. This apparent paradoxical decrease has also been described in mice submitted to 6 weeks of moderate-intensity treadmill exercise [46]. This decrease could be interpreted as an adaptation to exercise, in particular with an improvement of the Cori cycle (between the muscle and liver). In support of this idea, authors found an increase in lactate transporter in the liver, during this study. Therefore, it appears that lactate is not mediating the observed hippocampal changes. However, we cannot exclude an increment of blood lactate at the beginning of the exercise protocol, leading to hippocampal changes.

GFAP is a highly regulated protein, whose expression is induced by brain development and injury [47]. We observed a decrease in hippocampal GFAP, induced by physical exercise. At this moment, our work hypothesis is that corticosterone, which we found increased in our protocol of physical exercise, can downregulate GFAP expression. In fact, GFAP levels are negatively regulated by glucocorticoids in the rat hippocampus (see [48], for a review). Moreover, we can speculate that this downregulation of GFAP (induced by physical exercise) could be associated with other neuronal changes that accompany GFAP downregulated conditions, such as neurite outgrowth $[49,50]$. Therefore, we may suggest that GFAP decreases as in indirect signal of neuronal plasticity in the rat hippocampus in response to treadmill exercise. It has been suggested that GFAP expression has an important role in astrocyte-neural interactions [51]; however, the consequence of this change in the cognitive process remains unclear. In contrast to GFAP, S100B was not changed by physical exercise in the rat hippocampus, confirming previous reports $[21,23]$. This protein is secreted by astrocytes and has a trophic extracellular effect on neuron and glial cells [52, 53]. Moreover, no changes in basal in vitro secretion of this protein in the hippocampal slices were observed, in agreement with unaltered levels of cerebrospinal fluid S100B in rats submitted to treadmill exercise [20].

BDNF is a neurotrophin, associated with brain plasticity that is induced by physical exercise $[2,9,54]$. This neurotrophin had no effect on GFAP expression in the retina [55] but was able to reduce GFAP expression in the cerebral cortex after ischemia [56]. On the other hand, BDNF was able to restore hippocampal GFAP levels reduced by chronic unpredictable mild stress in rats [57]. Under these conditions, we did not observe any significant physical exercise-induced changes in BDNF that could be related to decreased GFAP levels. Corticosterone is able to transiently downregulate
BDNF mRNA in the hippocampus [58], possibly contributing, in this study, to maintain the levels of this neurotrophin unaltered. Moreover, other studies using moderate acute physical exercise (for $1 \mathrm{~h}$ ) [59] (or for 2 weeks) [60, 61] did not find changes in hippocampal BDNF either.

In addition to the decrease in GFAP, we found an increment in GS activity. Whether this effect also depends on corticosterone remains unclear, but it has been reported that expression of GFAP and GS in vivo shows opposite responses to corticosterone in the hippocampus [62]. However, there is not enough information about changes in these proteins induced by physical exercise. Recently, we found that GS activity was increased by caloric restriction but not by physical exercise (treadmill running, 20 min sessions, for 12 weeks) [23]. This could suggest that the GS increment induced by the 4-week protocol of treadmill running could be transitory (as well as GFAP decrease). The increased GS activity induced by physical exercise could be beneficial in the brain; this enzyme is involved in the modulation of the turnover of glutamate through the glutamate-glutamine cycle and detoxification of ammonia, and its decrease has been observed in neurodegenerative disorders [63]. The enzyme activity is negatively modulated by nitration on the tyrosine residue, through a NMDA receptor-mediated cGMP-NO signal transduction pathway (see Butterworth [64] for a review).

Note that while NO works as a physiological mediator, excessive NO release due to the high expression of inducible NO synthase (iNOS) mediates inflammatory/degenerative brain diseases [65]. Herein, we observed a decrease in NO content (measured by nitrite content), which in turn could be connected to the increased GS activity. In agreement with these findings, physical exercise was able to prevent the increase in hippocampal NO induced by intracerebroventricular streptozotocin administration [20]. The mechanism for this is unclear, but it may also be mediated by corticosterone. In support of this hypothesis, swimming exercise induced a decrease in the rat hippocampal iNOS, possibly dependent on corticosterone [66]. Other experimental evidence reinforces the importance of treadmill exercise for decreasing iNOS in murine models of neurodegenerative diseases, such as Parkinson's [67] and Alzheimer's diseases [68].

Considering the close metabolic relationship between glutamine and glutamate, we also investigated glutamate uptake in hippocampal slices of exercised rats. No changes in glutamate uptake were observed, in agreement with our previous study using a longer protocol of physical exercise [23]. Hippocampal GSH content and ROS (data not shown) were not altered by physical exercise under our conditions. A glutathione decrease could suggest oxidative stress, and an increment induced by physical exercise has been interpreted as signal of improvement in antioxidant defense $[20,23]$. An elegant study has shown that moderate treadmill running did not change the basal content of glutathione, but it was able to reverse the decrease in glutathione induced by intraperitoneal buthionine-sulfoximine administration [69]. Another important aspect for brain activity, during physical exercise, is the increment cerebral blood flow that is commonly related to energetic substrate uptake [70]. For example, diabetic type 
2 patients may benefit from physical exercise, as muscles dramatically increase glucose uptake [71]. However, brain alterations induced by physical alterations have not been evaluated, and potential changes in the hypometabolism that precedes neurodegenerative diseases (see Cunnane, et al. [72]) could be very useful to improve life quality. Herein, no changes were observed in the glucose uptake of hippocampal slices of healthy exercised animals (data not shown). However, this parameter should be investigated in brain disease models, where physical exercise has been proposed as a neuroprotective strategy (e.g., Rodrigues et al. [20]).

\section{Conclusions}

Our data show that moderate treadmill exercise was able to induce a decrease in GFAP content (evaluated by ELISA and immunohistochemistry) and to increase GS activity. These changes could be mediated by corticosterone, whose levels were elevated in serum. BDNF, another putative regulator of the expression of these astroglial proteins, was not altered in hippocampal tissue. Moreover, treadmill exercise caused a decrease in NO content. We did not observe changes in other astroglial parameters such as glutamate uptake, GSH content, and S100B protein. Taken together, these data indicate specific changes in astrocyte markers induced by physical exercise, the importance of astrocytes in brain plasticity, as well as reinforce the relevance of physical exercise as a strategy for neuroprotection.

\section{Conflict of Interests}

The authors declare that here is no conflict of interests.

\section{Acknowledgments}

This work was supported by the Conselho Nacional de Desenvolvimento Científico e Tecnológico (CNPq), Coordenação de Aperfeiçoamento de Pessoal de Nível Superior (CAPES), FINEP/Rede IBN 01.06.0842-00, and National Institute of Science and Technology for Excitotoxicity and Neuroprotection (INCTEN).

\section{References}

[1] H. van Praag, "Exercise and the brain: something to chew on," Trends in Neurosciences, vol. 32, no. 5, pp. 283-290, 2009.

[2] Q. Ma, "Beneficial effects of moderate voluntary physical exercise and its biological mechanisms on brain health," Neuroscience Bulletin, vol. 24, no. 4, pp. 265-270, 2008.

[3] H. van Praag, B. R. Christie, T. J. Sejnowski, and F. H. Gage, "Running enhances neurogenesis, learning, and long-term potentiation in mice," Proceedings of the National Academy of Sciences of the United States of America, vol. 96, no. 23, pp. 13427-13431, 1999.

[4] M. K. Jedrziewski, V. M. Y. Lee, and J. Q. Trojanowski, "Physical activity and cognitive health," Alzheimer's and Dementia, vol. 3, no. 2, pp. 98-108, 2007.
[5] Z. Radák, T. Kaneko, S. Tahara et al., "Regular exercise improves cognitive function and decreases oxidative damage in rat brain," Neurochemistry International, vol. 38, no. 1, pp. 17-23, 2001.

[6] H. Ogonovszky, I. Berkes, S. Kumagai et al., "The effects of moderate-, strenuous- and over-training on oxidative stress markers, DNA repair, and memory, in rat brain," Neurochemistry International, vol. 46, no. 8, pp. 635-640, 2005.

[7] E. T. Ang, G. S. Dawe, P. T. H. Wong, S. Moochhala, and Y. $\mathrm{K} . \mathrm{Ng}$, "Alterations in spatial learning and memory after forced exercise," Brain Research, vol. 1113, no. 1, pp. 186-193, 2006.

[8] L. Grace, S. Hescham, L. A. Kellaway, K. Bugarith, and V. A. Russell, "Effect of exercise on learning and memory in a rat model of developmental stress," Metabolic Brain Disease, vol. 24, no. 4, pp. 643-657, 2009.

[9] C. W. Cotman and N. C. Berchtold, "Exercise: a behavioral intervention to enhance brain health and plasticity," Trends in Neurosciences, vol. 25, no. 6, pp. 295-301, 2002.

[10] A. D. Smith and M. J. Zigmond, "Can the brain be protected through exercise? Lessons from an animal model of parkinsonism," Experimental Neurology, vol. 184, no. 1, pp. 31-39, 2003.

[11] J. A. Zoladz and A. Pilc, "The effect of physical activity on the brain derived neurotrophic factor: from animal to human studies," Journal of Physiology and Pharmacology, vol. 61, no. 5, pp. 533-541, 2010.

[12] V. Parpura and R. Zorec, "Gliotransmission: exocytotic release from astrocytes," Brain Research Reviews, vol. 63, no. 1-2, pp. 83-92, 2010.

[13] G. Perea and A. Araque, "GLIA modulates synaptic transmission," Brain Research Reviews, vol. 63, no. 1-2, pp. 93-102, 2010.

[14] R. Dringen, "Metabolism and functions of glutathione in brain," Progress in Neurobiology, vol. 62, no. 6, pp. 649-671, 2000.

[15] J. Li, Y. H. Ding, J. A. Rafols, Q. Lai, J. P. McAllister II, and Y. Ding, "Increased astrocyte proliferation in rats after running exercise," Neuroscience Letters, vol. 386, no. 3, pp. 160-164, 2005.

[16] M. E. Gibbs, D. Hutchinson, and L. Hertz, "Astrocytic involvement in learning and memory consolidation," Neuroscience and Biobehavioral Reviews, vol. 32, no. 5, pp. 927-944, 2008.

[17] J. Correale and A. Villa, "Cellular elements of the blood-brain barrier," Neurochemical Research, vol. 34, no. 12, pp. 2067-2077, 2009.

[18] M. Bergami, S. Santi, E. Formaggio et al., "Uptake and recycling of pro-BDNF for transmitter-induced secretion by cortical astrocytes," Journal of Cell Biology, vol. 183, no. 2, pp. 213-221, 2008.

[19] P. G. Haydon and G. Carmignoto, "Astrocyte control of synaptic transmission and neurovascular coupling," Physiological Reviews, vol. 86, no. 3, pp. 1009-1031, 2006.

[20] L. Rodrigues, M. F. Dutra, J. Ilha et al., "Treadmill training restores spatial cognitive deficits and neurochemical alterations in the hippocampus of rats submitted to an intracerebroventricular administration of streptozotocin," Journal of Neural Transmission, vol. 117, no. 11, pp. 1295-1305, 2010.

[21] P. N. de Senna, J. Ilha, P. P. A. Baptista et al., "Effects of physical exercise on spatial memory and astroglial alterations in the hippocampus of diabetic rats," Metabolic Brain Disease, vol. 26, no. 4, pp. 269-279, 2011.

[22] E. T. Ang, P. T. H. Wong, S. Moochhala, and Y. K. Ng, "Cytokine changes in the horizontal diagonal band of broca in the septum after running and stroke: a correlation to glial activation," Neuroscience, vol. 129, no. 2, pp. 337-347, 2004. 
[23] K. Santin, R. F. da Rocha, F. Cechetti et al., "Moderate exercise training and chronic caloric restriction modulate redox status in rat hippocampus," Brain Research, vol. 1421, pp. 1-10, 2011.

[24] P. R. Burghardt, L. J. Fulk, G. A. Hand, and M. A. Wilson, "The effects of chronic treadmill and wheel running on behavior in rats," Brain Research, vol. 1019, no. 1-2, pp. 84-96, 2004.

[25] R. M. Melo, E. Martinho Jr., and L. C. Michelini, "Traininginduced, pressure-lowering effect in SHR: wide effects on circulatory profile of exercised and nonexercised muscles," Hypertension, vol. 42, no. 4, pp. 851-857, 2003.

[26] D. Scopel, C. Fochesatto, H. Cimarosti et al., "Exercise intensity influences cell injury in rat hippocampal slices exposed to oxygen and glucose deprivation," Brain Research Bulletin, vol. 71, no. 1-3, pp. 155-159, 2006.

[27] C. B. O. Netto, S. Conte, M. C. Leite et al., "Serum S100B protein is increased in fasting rats," Archives of Medical Research, vol. 37, no. 5, pp. 683-686, 2006.

[28] M. C. Leite, F. Galland, G. Brolese et al., "A simple, sensitive and widely applicable ELISA for S100B: methodological features of the measurement of this glial protein," Journal of Neuroscience Methods, vol. 169, no. 1, pp. 93-99, 2008.

[29] F. Tramontina, M. C. Leite, K. Cereser et al., "Immunoassay for glial fibrillary acidic protein: antigen recognition is affected by its phosphorylation state," Journal of Neuroscience Methods, vol. 162, no. 1-2, pp. 282-286, 2007.

[30] A. Swarowsky, L. Rodrigues, R. Biasibetti et al., "Glial alterations in the hippocampus of rats submitted to ibotenicinduced lesion of the nucleus basalis magnocellularis," Behavioural Brain Research, vol. 190, no. 2, pp. 206-211, 2008.

[31] A. P. Thomazi, G. F. Godinho, J. M. Rodrigues et al., "Ontogenetic profile of glutamate uptake in brain structures slices from rats: sensitivity to guanosine," Mechanisms of Ageing and Development, vol. 125, no. 7, pp. 475-481, 2004.

[32] A. M. Feoli, I. Siqueira, L. M. V. Almeida et al., "Brain glutathione content and glutamate uptake are reduced in rats exposed to pre- and postnatal protein malnutrition," Journal of Nutrition, vol. 136, no. 9, pp. 2357-2361, 2006.

[33] R. W. Browne and D. Armstrong, "Reduced glutathione and glutathione disulfide," Methods in Molecular Biology, vol. 108, pp. 347-352, 1998.

[34] J. M. Hevel and M. A. Marletta, "Nitric-oxide synthase assays," Methods in Enzymology, vol. 233, pp. 250-258, 1994.

[35] A. Quincozes-Santos, P. Nardin, D. F. Souza et al., "The janus face of resveratrol in astroglial cells," Neurotoxicity Research, vol. 16, no. 1, pp. 30-41, 2009.

[36] L. P. Garetto, E. A. Richter, M. N. Goodman, and N. B. Ruderman, "Enhanced muscle glucose metabolism after exercise in the rat: the two phases," The American Journal of Physiology, vol. 246, no. 6, pp. E471-475, 1984.

[37] F. A. Voltarelli, C. A. Gobatto, and M. A. de Mello, "Determination of anaerobic threshold in rats using the lactate minimum test," Brazilian Journal of Medical and Biological Research, vol. 35, no. 11, pp. 1389-1394, 2002.

[38] E. T. Ang and F. Gomez-Pinilla, "Potential therapeutic effects of exercise to the brain," Current Medicinal Chemistry, vol. 14, no. 24, pp. 2564-2571, 2007.

[39] A. T. U. Schaefers, K. Grafen, G. Teuchert-Noodt, and Y. Winter, "Synaptic remodeling in the dentate gyrus, CA3, CA1, subiculum, and entorhinal cortex of mice: effects of deprived rearing and voluntary running," Neural Plasticity, vol. 2010, Article ID 870573, 11 pages, 2010.
[40] M. Haber, L. Zhou, and K. K. Murai, "Cooperative astrocyte and dendritic spine dynamics at hippocampal excitatory synapses," Journal of Neuroscience, vol. 26, no. 35, pp. 8881-8891, 2006.

[41] E. C. Beattie, D. Stellwagen, W. Morishita et al., "Control of synaptic strength by glial TNF $\alpha$," Science, vol. 295, no. 5563, pp. 2282-2285, 2002.

[42] A. Panatier, D. T. Theodosis, J. P. Mothet et al., "Glia-derived Dserine controls NMDA receptor activity and synaptic memory," Cell, vol. 125, no. 4, pp. 775-784, 2006.

[43] J. Middeldorp and E. M. Hol, "GFAP in health and disease," Progress in Neurobiology, vol. 93, no. 3, pp. 421-443, 2011.

[44] C. W. Cotman, N. C. Berchtold, and L. A. Christie, "Exercise builds brain health: key roles of growth factor cascades and inflammation," Trends in Neurosciences, vol. 30, no. 9, pp. 464-472, 2007.

[45] G. van Hall, M. Strømstad, P. Rasmussen et al., "Blood lactate is an important energy source for the human brain," Journal of Cerebral Blood Flow and Metabolism, vol. 29, no. 6, pp. 1121-1129, 2009.

[46] E. Lezi, J. Lu, J. M. Burns, and R. H. Swerdlow, "Effect of exercise on mouse liver and brain bioenergetic infrastructures," Experimental Physiology, vol. 98, pp. 207-219, 2013.

[47] L. F. Eng, R. S. Ghirnikar, and Y. L. Lee, "Glial fibrillary acidic protein: GFAP-thirty-one years (1969-2000)," Neurochemical Research, vol. 25, no. 9-10, pp. 1439-1451, 2000.

[48] N. R. Nichols, D. Agolley, M. Zieba, and N. Bye, "Glucocorticoid regulation of glial responses during hippocampal neurodegeneration and regeneration," Brain Research Reviews, vol. 48, no. 2, pp. 287-301, 2005.

[49] I. Rozovsky, M. Wei, D. J. Stone et al., "Estradiol (E2) enhances neurite outgrowth by repressing glial fibrillary acidic protein expression and reorganizing laminin," Endocrinology, vol. 143, no. 2, pp. 636-646, 2002.

[50] V. Menet, M. Giménez Y Ribotta, N. Chauvet et al., "Inactivation of the glial fibrillary acidic protein gene, but not that of vimentin, improves neuronal survival and neurite growth by modifying adhesion molecule expression," Journal of Neuroscience, vol. 21, no. 16, pp. 6147-6158, 2001.

[51] H. Tanaka, A. Katoh, K. Oguro et al., "Disturbance of hippocampal long-term potentiation after transient ischemia in GFAP deficient mice," Journal of Neuroscience Research, vol. 67, no. 1, pp. 11-20, 2002.

[52] C. A. Gonçalves, M. C. Leite, and P. Nardin, "Biological and methodological features of the measurement of S100B, a putative marker of brain injury," Clinical Biochemistry, vol. 41, no. 10-11, pp. 755-763, 2008.

[53] R. Donato and C. W. Heizmann, "S100B protein in the nervous system and cardiovascular apparatus in normal and pathological conditions," Cardiovascular Psychiatry and Neurology, vol. 2010, Article ID 929712, 2 pages, 2010.

[54] P. Rasmussen, P. Brassard, H. Adser et al., "Evidence for a release of brain-derived neurotrophic factor from the brain during exercise," Experimental Physiology, vol. 94, no. 10, pp. 1062-1069, 2009.

[55] H. Chen and A. J. Weber, "Expression of glial fibrillary acidic protein and glutamine synthetase by Müller cells after optic nerve damage and intravitreal application of brain-derived neurotrophic factor," GLIA, vol. 38, no. 2, pp. 115-125, 2002.

[56] W. R. Schäbitz, C. Berger, R. Kollmar et al., "Effect of brainderived neurotrophic factor treatment and forced arm use on functional motor recovery after small cortical ischemia," Stroke, vol. 35, no. 4, pp. 992-997, 2004. 
[57] Y. Ye, G. Wang, H. Wang, and X. Wang, "Brain-derived neurotrophic factor (BDNF) infusion restored astrocytic plasticity in the hippocampus of a rat model of depression," Neuroscience Letters, vol. 503, no. 1, pp. 15-19, 2011.

[58] H. Soya, T. Nakamura, C. C. Deocaris et al., "BDNF induction with mild exercise in the rat hippocampus," Biochemical and Biophysical Research Communications, vol. 358, no. 4, pp. 961-967, 2007.

[59] M. Goekint, B. Roelands, E. Heyman, R. Njemini, and R. Meeusen, "Influence of citalopram and environmental temperature on exercise-induced changes in BDNF," Neuroscience Letters, vol. 494, no. 2, pp. 150-154, 2011.

[60] F. Cechetti, C. Fochesatto, D. Scopel et al., "Effect of a neuroprotective exercise protocol on oxidative state and BDNF levels in the rat hippocampus," Brain Research, vol. 1188, no. 1, pp. 182-188, 2008.

[61] A. F. B. Ferreira, C. C. Real, A. C. Rodrigues, A. S. Alves, and L. R. G. Britto, "Short-term, moderate exercise is capable of inducing structural, BDNF-independent hippocampal plasticity," Brain Research, vol. 1425, pp. 111-122, 2011.

[62] N. J. Laping, N. R. Nichols, J. R. Day, S. A. Johnson, and C. E. Finch, "Transcriptional control of glial fibrillary acidic protein and glutamine synthetase in vivo shows opposite responses to corticosterone in the hippocampus," Endocrinology, vol. 135, no. 5, pp. 1928-1933, 1994.

[63] S. R. Robinson, "Changes in the cellular distribution of glutamine synthetase in Alzheimer's disease," Journal of Neuroscience Research, vol. 66, no. 5, pp. 972-980, 2001.

[64] R. F. Butterworth, "Altered glial-neuronal crosstalk: cornerstone in the pathogenesis of hepatic encephalopathy," Neurochemistry International, vol. 57, no. 4, pp. 383-388, 2010.

[65] G. C. Brown, "Mechanisms of inflammatory neurodegeneration: INOS and NADPH oxidase," Biochemical Society Transactions, vol. 35, no. 5, pp. 1119-1121, 2007.

[66] X. Liu, J. Yang le, S. J. Fan, H. Jiang, and F. Pan, "Swimming exercise effects on the expression of HSP70 and iNOS in hippocampus and prefrontal cortex in combined stress," Neuroscience Letters, vol. 476, no. 2, pp. 99-103, 2010.

[67] Y.-H. Sung, S.-C. Kim, H.-P. Hong et al., "Treadmill exercise ameliorates dopaminergic neuronal loss through suppressing microglial activation in Parkinson's disease mice," Life Sciences, vol. 91, no. 25-26, pp. 1309-1316, 2012.

[68] Y. H. Leem, Y. I. Lee, H. J. Son, and S. H. Lee, "Chronic exercise ameliorates the neuroinflammation in mice carrying NSE/htau23," Biochemical and Biophysical Research Communications, vol. 406, no. 3, pp. 359-365, 2011.

[69] S. Salim, N. Sarraj, M. Taneja, K. Saha, M. V. Tejada-Simon, and G. Chugh, "Moderate treadmill exercise prevents oxidative stress-induced anxiety-like behavior in rats," Behavioural Brain Research, vol. 208, no. 2, pp. 545-552, 2010.

[70] J. S. Querido and A. W. Sheel, "Regulation of cerebral blood flow during exercise," Sports Medicine, vol. 37, no. 9, pp. 765-782, 2007.

[71] M. L. Goodwin, "Blood glucose regulation during prolonged, submaximal, continuous exercise: a guide for clinicians," Journal of Diabetes Science and Technology, vol. 4, no. 3, pp. 694-705, 2010.

[72] S. Cunnane, S. Nugent, M. Roy et al., "Brain fuel metabolism, aging, and Alzheimer's disease," Nutrition, vol. 27, no. 1, pp. 3-20, 2011. 

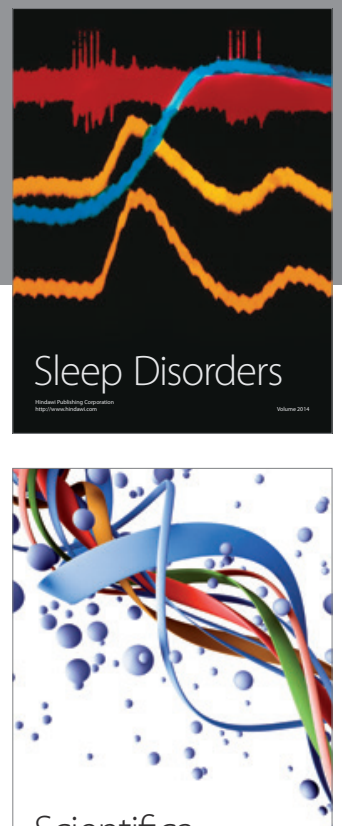

Scientifica
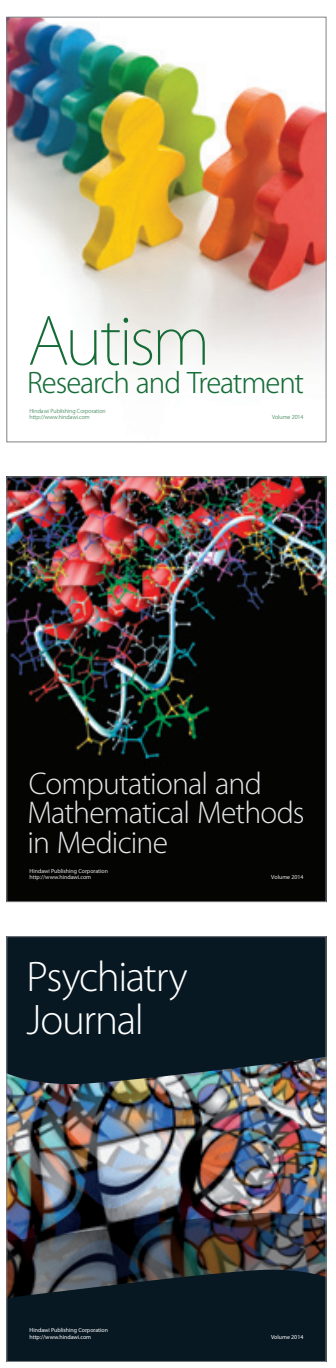
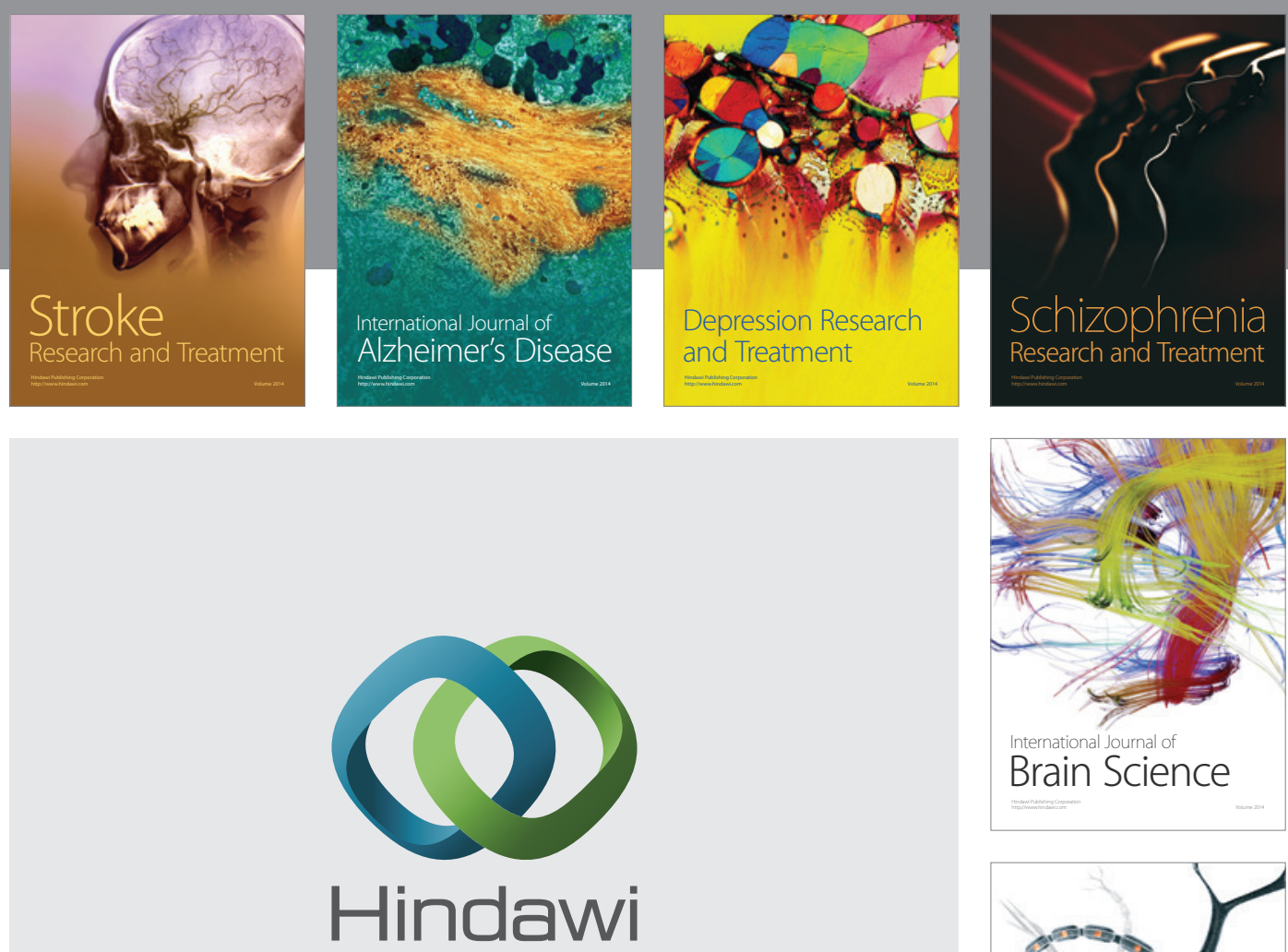

Submit your manuscripts at

http://www.hindawi.com
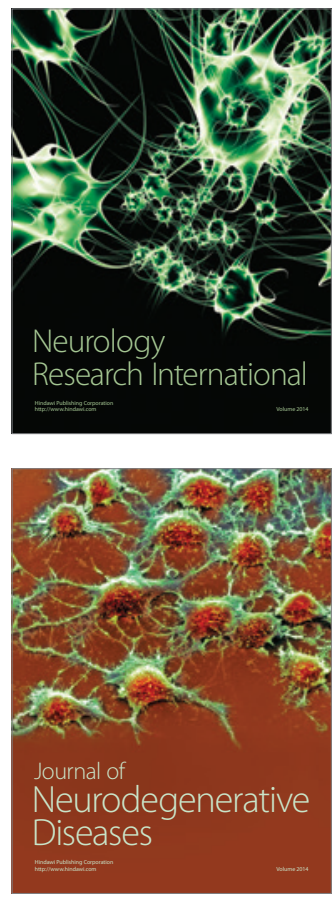

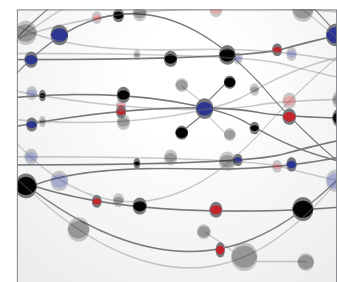

The Scientific World Journal
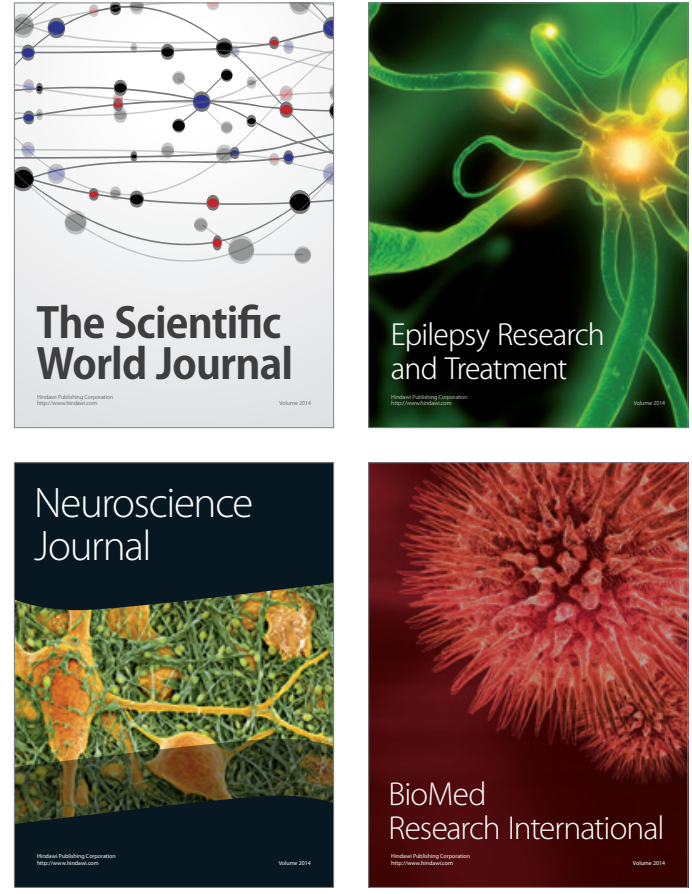

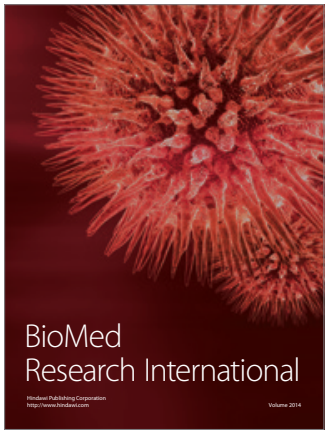

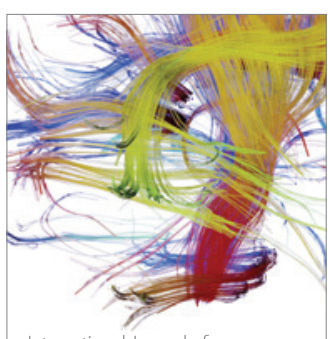

Brain Science

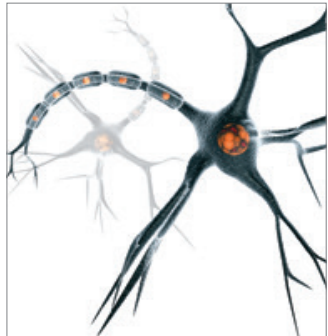

Neural Plasticity
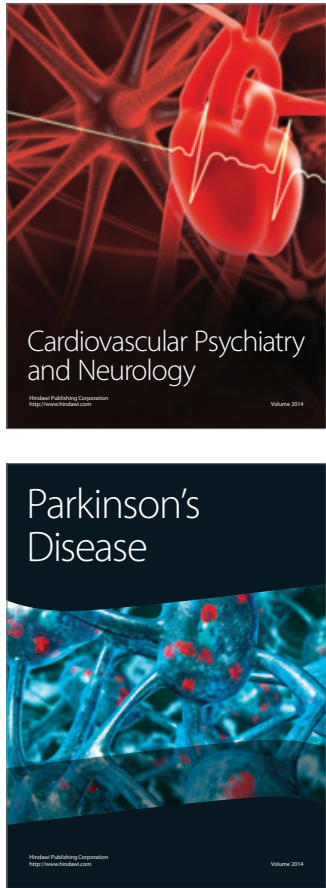